\title{
Understanding the Relationship between Social Anxiety and Personality
}

\author{
Ruhee Contractor $^{1}$, Sejal Sarkar ${ }^{2}$ \\ ${ }^{1,2}$ Department of Psychology, K.C College, Mumbai. \\ Corresponding author: Ms. Ruhee Contractor \\ Email-ruhee.contractor@gmail.com
}

\begin{abstract}
Background: Previous studies on the relationship between social anxiety and personality have found that certain components of The Big Five such as neuroticism and extraversion are related to social anxiety. There is little data available on this relationship of social anxiety in Indian university students even though, past researchers have found that social phobia leads to impairment in various aspects of life. Thus, this research tried to narrow these gaps and explore the links between social anxiety and personality in Indian university students.

Methods: The sample consisted of $\mathrm{N}=121$ participants and they were asked to complete two questionnaires - The Big Five Factor Inventory and the Liebowitz Social Anxiety Scale (LSAS). A subscale of the LSAS i.e. total avoidance was measured to find its relationship with the Big Five. Pearson's correlation and multiple regressions were used to analyse the data.

Results: Findings indicated that personality, in particular, high neuroticism and low extraversion, may play an important role in the manifestation of social anxiety. Interpretations and implications of predictive importance of the interaction of personality traits and avoidance in anxiety are discussed, and further speculations about different interventions and cross-cultural studies have been put forth.

Conclusion:The strength of this study is that it is one of the few research studies done in India which look at this relationship. Such a high prevalence was not expected as India is a collectivistic culture and it is a norm and an expectation to socialize.
\end{abstract}

Keywords: Social anxiety, personality, big five, avoidance, LSAS.

(Paper received $-4^{\text {th }}$ January 2018, Peer review completed $-12^{\text {th }}$ January 2018)

(Accepted $-18^{\text {th }}$ January 2018)

\section{INTRODUCTION}

According to Wiggins and Pincus, the introduction of the Big Five taxonomy brought about renewed interest in studying the links between personality and adult psychopathology [1]. However, to date, few studies in India have examined the prospective relation between the constructs - personality traits and its relationship with social anxiety and also its relationship with avoidance that is a sub-aspect of social anxiety; both of which are necessary to help further our current understanding of personality- social anxiety relations in the context of Indian university students.

To narrow these gaps in empirical knowledge, this study examined the relationship between social anxiety and avoidance and their associations with personality dimensions. The present study explores the relationship between social phobia and personality in undergraduate students of some college of Mumbai, India. It studies various factors such as personality traits, total social anxiety and avoidance as a subscale of social anxiety. 


\section{Variables used in research Personality}

Weinberg and Gould discuss personality as "the characteristics or blend of characteristics that make a person unique." It thus, refers to the individual differences in characteristic patterns of thinking, feeling and behaving. According to Funder, the big five model given by Costa and McCrae is currently the best approximation of the basic trait dimensions and is therefore, most commonly used personality scale [2-3]. The five components are as follows:

Neuroticism/Emotional Stability: Neuroticism refers to the tendency to experience negative affects such as fear, sadness, embarrassment, anger, guilt, disgust and distress [4]. A high Neuroticism score indicates that a person is prone to having irrational ideas, being less able to control impulses, and coping poorly with stress.

Extraversion: Extroverts are characterized through various traits - sociable, assertive, talkative etc. Introverts on the other hand are reserve, independent and prefer monotony.

Agreeableness: An agreeable person is fundamentally altruistic, sympathetic to others and eager to help them, and in return believes that others will be equally helpful [3]. The person low on agreeableness is egocentric, skeptical and competitive [5].

Openness to experience: Openness to experience is the trait, which relates the extent to which individuals are open to fantasies, aesthetics, feelings, as well as novel actions, ideas, and values [3].

Conscientiousness: The six facets that correspond to conscientiousness relate to the degree to which individuals are competent, methodical--preferring order and structure, dutiful, motivated to achieve goals, disciplined, and deliberate or considered [3].Low scorers may be characterized by a laid-back attitude and lack of motivation for success.

\section{Social Anxiety}

Social anxiety is the fear of being judged and evaluated negatively by other people, and, as a result, leads to avoidance. Social anxiety can lead to feelings of inadequacy, inferiority, embarrassment as well as humiliation. There has been an increased research interest in this field, ever since its inclusion in DSM III, in 1980. Some people experience anxiety in most social situations. For others, anxiety is connected to specific social situations, such as speaking to strangers, mingling at parties, or performing in front of an audience etc. It is characterized by various emotional, physical and behavioural symptoms like extreme self-consciousness, fear of humiliation, hot or cold flashes, nausea, calling in sick to skip situations etc.

\section{Hypotheses}

There will be a relationship between social anxiety and personality

There will be an association between total avoidance and personality.

There will be no significant prediction of social anxiety by neuroticism, extraversion and conscientiousness.

There will be no significant prediction of avoidance by neuroticism, extraversion and conscientiousness.

\section{Operational definitions}

Social Anxiety: The total social anxiety was measured by calculating the sum of the Liebowitz Social Anxiety Scale (LSAS); wherein the decision criteria was any participant scoring above the total score of 30 for Total Social Anxiety on this scale.

Personality: was measured by using the Big Five Factor Questionnaire.

Previous studies have looked at the relationship between dimensions of five-factor models of personality with social anxiety. The personality traits that were found to have significant relations were neuroticism and extraversion. In a study on personality factors associated with generalized and non-generalized social anxiety suggests that generalized social anxiety is more related to personality dimensions reflecting neuroticism [6]. Research on Anxiety and depressive disorders and the five-factor model of personality in a community sample investigated and found that social phobia has high correlation with neuroticism and low with extraversion and facets of agreeableness (trust) and conscientiousness (self-discipline, competence) [7]. 
A twin study examined the links between neuroticism and extraversion and the genetic and environmental risks for social phobia. Genetic correlations also suggest a relationship between social phobia and personality. It was found to be high and positive for neuroticism, moderate and negative correlations were seen among extraversion and social phobia [7]. A cross-cultural study of a non -clinical sample of Chinese and American college students indicated that shame and personality factors, such as neuroticism and introversion-extraversion, were related to social anxiety symptoms in Chinese college students [8].

S.C. Kaplan and others (2015) also found that social anxiety correlated positively with neuroticism, negatively with extraversion, and had weaker relationships with agreeableness, openness, and trust [9].

Thus, looking at the various past researches we find that high neuroticism and low extraversion and certain facets of conscientiousness may be important factors in trying to understand the links between personality with social anxiety.

The facet of avoidance as an important factor in diagnosing social anxiety was added in the definition of DSM IV TR (1994). This then led to an increased curiosity of researchers to study avoidance in social anxiety and the manifestations of avoidance in several different forms.

Even though avoidance has been studied in different forms only few studies have focused on its relationship with the Big Five. Therefore this study tries to understand the link between these two dimensions which can be further helpful to elucidate social anxiety and its manifestations.

\section{METHODOLOGY}

\section{Participants}

The sample consisted of 121 participants between the age group of 18-22 years from a South Mumbai College. The participants were degree college students belonging to different fields i.e. Arts, Commerce and Science. All participants gave their consent prior to the data collection.

\section{Measures}

Personality: The Big Five Inventory (BFI) was used to determine the different aspects of the participants' personality. The BFI is a 44-item measure that yields a score for each of the Big Five personality factors. The BFI was deemed to be a good choice for the current study as it has strong psychometric properties. Social Anxiety: The Liebowitz Social Anxiety Scale (LSAS; Liebowitz 1987) [10] assesses fear and avoidance in 24 situations in order to assist the diagnosis of social anxiety disorder. The purpose is to assess the range of social interaction and performance situations that elicit fear of these situations by people with this disorder. The scale is composed of 24 items divided into 2 subscales -13 items inquiring about performance situations (e.g. giving a report to a group, eating in public places) while the remaining 11 situations assess social interaction situations (e.g. going to a party, meeting strangers).

\section{Data Collection}

The data was collected from November 2016 to March 2017 in the campus of some college. The tests were handed out to students manually during the college hours

\section{RESULTS AND DISCUSSION}

Table 1- Correlation coefficients between social anxiety score and total avoidance scores on LSAS and Big 5 Factors of personality

\begin{tabular}{|l|l|l|l|l|l|}
\hline & $\begin{array}{l}\text { Openness } \\
\text { experience }\end{array}$ & conscientiousness & extraversion & agreeableness & neuroticism \\
\hline $\begin{array}{l}\text { Social } \\
\text { Anxiety }\end{array}$ & -0.03 & $-0.32^{* * *}$ & $-0.37^{* * *}$ & $-0.29^{* *}$ & $0.37^{* * *}$ \\
\hline Avoidance & -0.02 & $-0.33^{* * *}$ & $-0.4^{* * *}$ & $-0.24^{*}$ & $0.39^{* * *}$ \\
\hline
\end{tabular}

*** Significant at the 0.001 level, ** significant at the 0.01 level, * significant at the 0.05 level 
Previous research has repeatedly found a positive link between social anxiety and facets of personality i.e. neuroticism, extraversion [7]. The current research seeks to investigate these links that have not been sufficiently considered in the Indian context.

The first hypothesis states the link between personality factors and total social anxiety experienced by a non-clinical sample of students. Through data analysis, we found out that social anxiety is linked to facets of neuroticism, conscientiousness and extraversion to a moderate level as seen in table no 2. Neuroticism and social anxiety showed a positive moderate correlation of 0.37 suggesting that an individual with a high score on this dimension is likely to also have a high score on social anxiety. Extraversion, on the other hand, showed an inverse moderate correlation of -0.37 suggests that if the individual scores low on the extraversion scale (introvert) there is an increase in the likelihood of experiencing social anxiety.Social anxiety and conscientiousness displayed a moderate and inverse correlation of -0.32 suggests that an increase in one variable (social anxiety) leads to a decrease in the second variable (conscientiousness) and a decrease of the variable (social anxiety) would lead to an increase of the conscientiousness variable.

With reference to table 2, it was found that there is a moderate, positive correlation of 0.39 between Neuroticism and avoidance, indicating that to a certain extent, an increase in emotional instability reflects an increase in avoidance of social situations and performance-oriented tasks.

Results suggest that, for the given sample, there is a moderate, negative correlation of -0.33 between avoidance and conscientiousness. This indicates that an individual is more likely to avoid social situations and performance-oriented tasks if they have low conscientiousness. The rationale behind this that different aspect of conscientiousness includes aiming for goal achievement and following social decorum [11]. Therefore, individuals with low conscientiousness are less motivated to follow social rules in social situations or work hard to perform well in tasks. Thus, they may prefer to avoid these situations. Results also indicate a moderate, negative correlation of 0.4 between avoidance and extraversion.

Through data analysis, we found out that both social anxiety and avoidance were moderately linked with facets of neuroticism, conscientiousness and extraversion. But correlation only predicts the direction and magnitude of the linkage between two variables.

Multiple regression analysis helps assess the associations between two or more variables, as well as helps predict the extent to which one variable can help predict another. Thus, in order to check whether the presence of certain personality traits in an individual could help predict social anxiety, multiple regressions were conducted.

A multiple linear regression was calculated to predict social anxiety on basis of personality characteristics (based on neuroticism, extraversion and conscientiousness). A significant regression equation was found $(\mathrm{F}(3,27)=5.222, \mathrm{p}<0.006)$, with an $\mathrm{R}^{2}$ of 0.37 . Participants predicted social anxiety is equal to $4.76+1.95$ (neuroticism) - 1.05 (extraversion), where each is measured on the Liebowitz scale. Participants social anxiety increased 1.95 point for every neuroticism score, decreased 1.05 point for every extraversion score and was not affected by conscientiousness scores.

In predicting social anxiety, emotional instability and introversion appears to be the best predictor. Those who are more emotionally unstable as well as are introvert appear to exhibit more social anxiety than those who are more emotionally stable and extroverts. Interestingly, conscientiousness does not appear predictive of social anxiety.

A multiple linear regression was calculated to predict avoidance on basis of personality characteristics (based on neuroticism, extraversion and conscientiousness). A significant regression equation was found $(\mathrm{F}(3,116)=12.79, \mathrm{p}<0.0000003)$, with an $\mathrm{R}^{2}$ of 0.25 . Participants predicted avoidance is equal to $37.61+0.47$ (neuroticism) - 0.58 (extraversion), where each is measured on the Liebowitz scale. Participants social anxiety increased 0.47 point for every neuroticism score, decreased 0.58 point for every extraversion score, but didn't change with conscientiousness scores.

As seen in table 3 by regressing neuroticism, extraversion and conscientiousness on social anxiety we found that low extraversion was the best predictor of avoidance followed by neuroticism. However, conscientiousness did not appear to be predictive of avoidance as an aspect of social anxiety.

Neuroticism consists of tendencies toward negative affect particularly anxiety and depression as well as difficulty in controlling emotions and behaviours. The results of the data analysis indicated that to a certain extent, an increase in emotional instability reflected an increase in fear of social situations and 
performance-oriented tasks.Neuroticism and avoidance results of regression indicate that to a certain extent, an increase in emotional instability reflects an increase in avoidance of social situations and performance-oriented tasks

Extraversion, on the other hand, showed an inverse moderate correlation of -0.37 suggests that if the individual scores low on the extraversion scale (introvert) there is an increase in the likelihood of experiencing social anxiety. The findings of previous studies as well as the current study suggest that results scores of social anxiety and extraversion indicate that Individuals low in extraversion facet of personality are less comfortable with people and are less keen to participate in activities [12].This could translate into them wanting to avoid performances or social gatherings, hence resulting in a negative correlation between the two aspects. This could manifest in simple ways like fearing and/or avoiding eye contact, even in non-patient samples, as validated by a study conducted by Davidson and others. [13]. On the other hand, people with high Social Anxiety and associated avoidant behaviour talk less and are often worried or not confident of their social relations, and thus, opt to avoid them. This perhaps may also be one of the factors for an inverse correlation between extraversion and avoidance [14].

A reason for conscientiousness not being a predictive factor of social anxiety as well as avoidance is that people low on conscientiousness do not particularly fear or are not afraid of being in social situations itself thus other behaviours such as being less motivated to follow social decorum may not necessarily manifest into fear or avoidance of social situations and performance.

Table 2 - Multiple regression for variables predicting social anxiety

\begin{tabular}{|l|l|l|l|l|}
\hline & & Social Anxiety & & \\
\hline & Coefficients & Standard Error & $t$ Stat & $P$-value \\
\hline Variable & 4.76 & 40.07 & 0.12 & 0.9077 \\
\hline Conscientiousness & 0.74 & 0.87 & 0.85 & 0.4034 \\
\hline Extraversion & -1.05 & 0.48 & -2.19 & 0.0370 \\
\hline Neuroticism & 1.95 & 0.79 & 2.47 & 0.02022 \\
\hline R2 & 0.37 & & & \\
\hline F & 5.22 & Significance F & 0.006 & \\
\hline
\end{tabular}

Table 3 - Multiple regression for variables predicting avoidance

\begin{tabular}{|l|l|l|l|l|}
\hline & & Avoidance & & \\
\hline & Coefficients & Standard Error & $t$ Stat & $P$-value \\
\hline Variable & 37.60 & 10.07 & 3.74 & 0.0003 \\
\hline Conscientiousness & -0.25 & 0.19 & -1.29 & 0.20 \\
\hline Extraversion & -0.58 & 0.17 & -3.47 & 0.0007 \\
\hline Neuroticism & 0.47 & 0.19 & 2.43 & 0.0166 \\
\hline R2 & 0.25 & & & \\
\hline F & 12.79 & Significance F & 0.0000003 & \\
\hline
\end{tabular}

\section{CONCLUSION}

The sample consisted of total $\mathrm{N}=121$ participants. Out of the total sample, it was found that 103 people suffered from mild to moderate to high social anxiety. Thus, it was seen that the prevalence of social anxiety in Indian university students is quite high.

This study tried to understand and explore the relationship between social anxiety and personality. It was found that some traits such as neuroticism and extraversion, as explored in previous researches have a link with social anxiety [6-10]. An extension of the previous studies is that this study has also looked at one of the subscales of social anxiety i.e. avoidance and its relationship with personality. It was also observed that avoidance was linked with certain personality traits namely extraversion, conscientiousness and 
neuroticism. The strength of this study is that it is one of the few research studies done in India which look at this relationship. Such a high prevalence was not expected as India is a collectivistic culture and it is a norm and an expectation to socialize.

\section{Implications and Recommendations}

Health care providers, clinicians need to be aware of the relationship between personality traits and certain maladaptive behaviours, particularly avoidance due to social anxiety. This high rate of social anxiety if not looked into can prove to be a problem for individuals in the future in terms of careers, socialization and to some extent may even hamper their daily functioning. The study suggests connections between social anxiety and personality traits specifically the Big Five and may deserve further attention from researchers of this domain. Studies could also look at ways in which teachers, caregivers etc. can intervene at early stages to reduce the prevalence rate of Social Anxiety. The comorbidity of social anxiety with other disorders and its relationship with avoidant personality disorder can also be further studied

\section{Limitations}

The research study was conducted with a non-clinical sample from some college in Mumbai. The sample also has higher number of female respondents than male respondents. Therefore, these results can't be generalized. The questionnaires used Liebowitz Social Anxiety Scale and Five Factor Personality Inventory, employ self-report techniques and hence one doesn't know whether the responses are socially desirable ones or what the respondents actually feel. Also, because these are self-report questionnaires, the results reflect how the respondents view themselves and are not absolute scores.

\section{REFERENCES}

1. Wiggins JS, Pincus AL. Conceptions of personality disorders and dimensions of personality. Psychol Assess 1989;1(4):305-13.

2. Baumeister RF, Vohs KD, Funder DC. Psychology as the science of self-reports and finger movements: Whatever happened to actual behavior?. Perspect Psychol Sci 2007;2(4):396-403.

3. Costa PT, MacCrae RR. Revised NEO personality inventory (NEO PI-R) and NEO five-factor inventory (NEO-FFI): Professional manual. Psychological Assessment Resources, Incorporated; 1992.

4. Bienvenu OJ, Hettema JM, Neale MC, Prescott CA, Kendler KS. Low extraversion and high neuroticism as indices of genetic and environmental risk for social phobia, agoraphobia, and animal phobia. Am J Psychiatry 2007;164(11):1714-21.

5. McCrae RR, John OP. An introduction to the five- factor model and its applications. J Personality 1992;60(2):175-215.

6. Rothman S, Coetzer EP. The relationship between personality dimensions and job satisfaction. Management Dynamics: Journal of the Southern African Institute for Management Scientists. 2002;11(1):29-42.

7. Norton GR, Cox BJ, Hewitt PL, McLeod L. Personality factors associated with generalized and non-generalized social anxiety. Personal Individ Diff 1997;22(5):655-60.

8. Bienvenu OJ, Samuels JF, Costa PT, Reti IM, Eaton WW, Nestadt G. Anxiety and depressive disorders and the five- factor model of personality: A higher- and lower- order personality trait investigation in a community sample. Depress Anxiety 2004;20(2):92-7.

9. Zhong J, Wang A, Qian M, Zhang L, Gao J, Yang J, Li B, Chen P. Shame, personality, and social anxiety symptoms in Chinese and American nonclinical samples: a cross- cultural study. Depress Anxiety 2008;25(5):449-60.

10. Kaplan SC, Levinson CA, Rodebaugh TL, Menatti A, Weeks JW. Social anxiety and the Big Five personality traits: The interactive relationship of trust and openness. Cogn Behav Ther 2015;44(3):212-22. 
11. Jackson JJ, Wood D, Bogg T, Walton KE, Harms PD, Roberts BW. What do conscientious people do? Development and validation of the Behavioral Indicators of Conscientiousness (BIC). J Res Personality 2010;44(4):501-11.

12. Martin CR. Looking at Type: The Fundamentals. Gainesville, FL: Center for Applications of Psychological Type ; 2010.

13. Davidson JR, Miner CM, De Veaugh-Geiss J, Tupler LA, Colket JT, Potts NL. The brief social phobia scale: a psychometric evaluation. Psychol Med 1997;27(1):161-6.

14. Smoller JW, Tsuang MT. Panic and phobic anxiety: defining phenotypes for genetic studies. Am J Psychiatry 1998;155(9):1152-62.

15. Srivastava S, John OP, Gosling SD, Potter J. Development of personality in early and middle adulthood: Set like plaster or persistent change?. J Personal Soc Psychol 2003;84(5):1041-8.

Acknowledgements - We would like to sincerely thank Miss Jade Carvalho our mentor for her constant support.

Conflict of Interest $-\mathrm{Nil}$

Funding - Nil 